\title{
An extension for the model IMAZ for large absorption
}

\author{
M. Friedrich and G. Landauer \\ Graz University of Technology, Graz, Austria
}

(Received May 19, 2010; Revised December 7, 2010; Accepted December 14, 2010; Online published June 14, 2011)

\begin{abstract}
The empirical Ionospheric Model of the Auroral Zone (IMAZ) is based on more than 100,000 electron density profiles measured by the European Incoherent Scatter Radar EISCAT combined with about 100 from sounding rockets. The mathematical procedure applied is a neural network (NN) which works fine as long as one requests predictions from inside the so-called input space, but predicting situations outside it, i.e. for conditions not or only poorly covered by data, are in general utterly unrealistic. An analytical procedure is presented which reasonably extrapolates the NN results for conditions inadequately covered by input data.
\end{abstract}

Key words: Auroral zone, ionosphere, EISCAT, neural networks, riometer.

\section{Introduction}

In the auroral zone the ionosphere is more often disturbed than undisturbed, i.e. its densities will be larger than one expects based on the usual parameters such as solar zenith angle, season, and solar activity by which the ionosphere elsewhere can be characterised (e.g., IRI, Bilitza and Reinisch, 2008). The model IMAZ (McKinnell and Friedrich, 2007) is based on the first full solar cycle of data from the incoherent scatter radar EISCAT (both UHF and VHF) together with just over 100 profiles from sounding rockets using radio wave propagation data. The height is restricted to $140 \mathrm{~km}$ for the simple pragmatic reason that up to that height (arguably) steady state behaviour of the ionosphere can be assumed. The geophysical conditions entered with each electron density profile are solar zenith angle, geomagnetic time, and solar activity. The influence expected due to season and latitude are accounted for by using pressure rather than altitude. IMAZ uses a local model based on falling sphere and lidar measurements obtained from measurements from the Andøya Rocket Range $\left(69^{\circ} \mathrm{N}\right.$; Friedrich et al., 2004). Geomagnetic latitude is disregarded since all data are from the auroral zone, i.e. geomagnetic latitudes in the range from $61^{\circ}$ to $69^{\circ}$ but the geographic latitude ranges from $59^{\circ}$ (Ft. Churchill) to almost $70^{\circ}$ (oblique EISCAT beams tilted to the north). Because the auroral ionosphere behaves erratically, IMAZ uses two additional parameters to describe disturbances, namely the global geomagnetic in$\operatorname{dex} a_{\mathrm{p}}$ and the locally established riometer absorption. The magnetic disturbance represented by $a_{\mathrm{p}}$ which is available for three hour time slots is due to currents flowing in the $E$ region. Riometer absorption, on the other hand, is not only measured locally, but is available for exactly the same time slots in which the electron densities are measured. Ionospheric absorption originates in the $D$-region (typically cen-

Copyright (C) The Society of Geomagnetism and Earth, Planetary and Space Sciences (SGEPSS); The Seismological Society of Japan; The Volcanological Society of Japan; The Geodetic Society of Japan; The Japanese Society for Planetary Sciences; TERRAPUB.

doi: $10.5047 /$ eps.2010.12.008 tred near $90 \mathrm{~km})$.

In a simplified definition a $\mathrm{NN}$ is a multi-dimensional, weighted interpolation routine. In order to assess the legitimate range of geophysical conditions the median values of the inputs to IMAZ and the upper and lower quartiles are important to keep in mind.

The overwhelming majority of the data comes from EISCAT which has density thresholds somewhat below and above $10^{9} \mathrm{~m}^{-3}$ for VHF and UHF, respectively. Similarly, small values of riometer absorption critically depend on a properly determined Quiet Day Curve and are therefore considered uncertain. The net result is that the manually edited profiles have a lower boundary which only for large disturbances (large riometer absorption) reaches to low altitudes. Figure 1 shows a contour plot of the number of usable electron density values as a function of riometer absorption and altitude.

Under quiet conditions, however, the ionosphere at high latitudes will behave as at other latitudes, i.e. only determined by the solar zenith angle and solar activity. We designate such electron densities as True Quiet (TQ). Figure 2 demonstrates the procedure with which to obtain TQ electron densities, namely to establish the low density envelope and only allow it to vary with zenith angle and solar activity; at night any variation after sundown at the specific height is ignored. The full procedure involved in the establishment of TQ is given by Friedrich et al. (2004) and Egger (2004). The NN of IMAZ was trained not only with the data displayed in Fig. 1, but also with a TQ counterpart for each measured value. The height-riometer area for useful predictions thus now extends all the way to $0 \mathrm{~dB}$ riometer absorption (Fig. 3), but predictions for larger disturbances are still problematic.

\section{Behaviour under Median Conditions}

IMAZ is a primarily meant to predict/model the lower auroral ionosphere where notably the $D$-region crucially hinges on rocket borne measurements of electron densities. The "disturbance parameter" which describes the $D$-region 


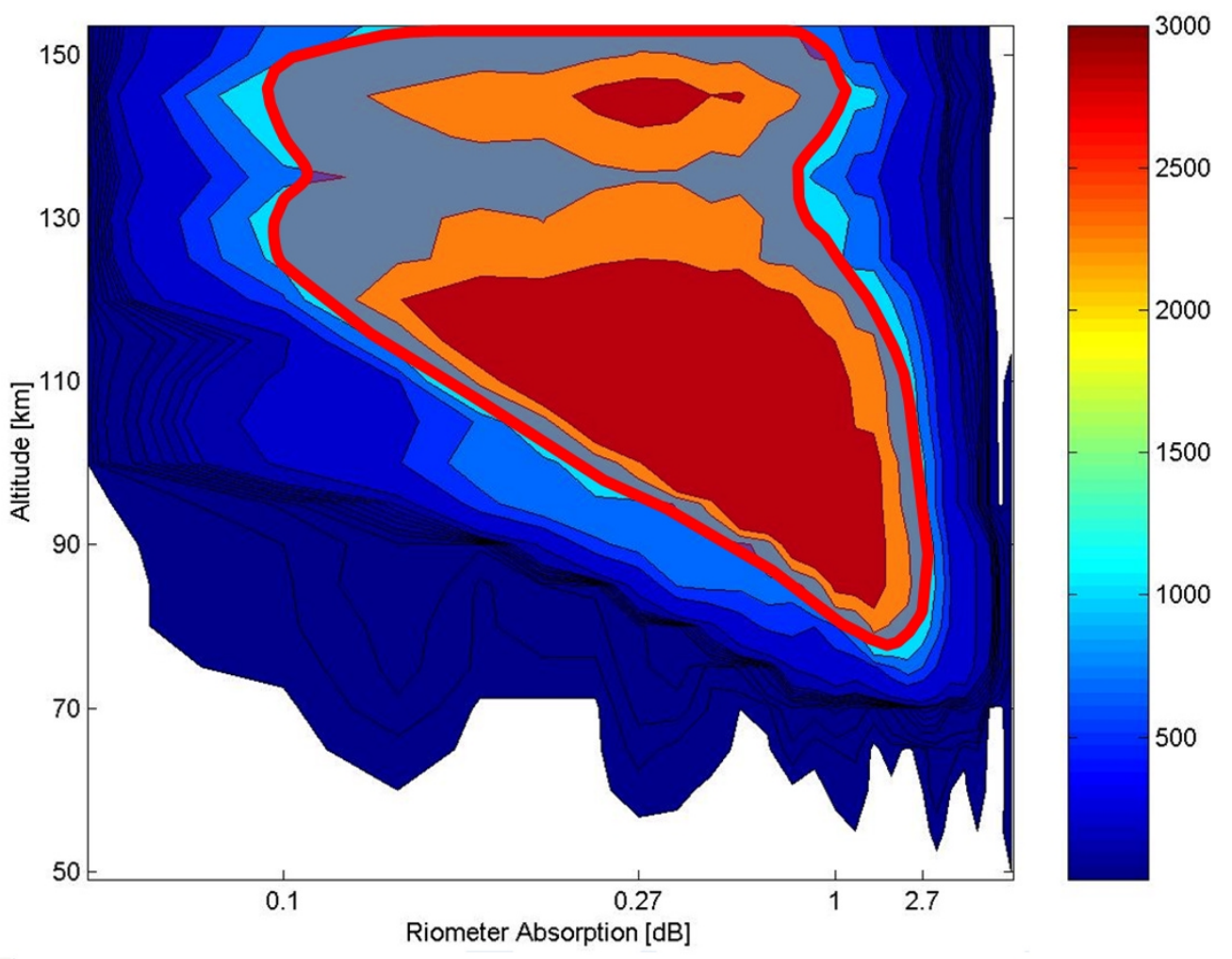

Fig. 1. Number of electron density values as a function of altitude and riometer absorption. Predictions for conditions inside the red line can be expect to be good from a model built on these data.

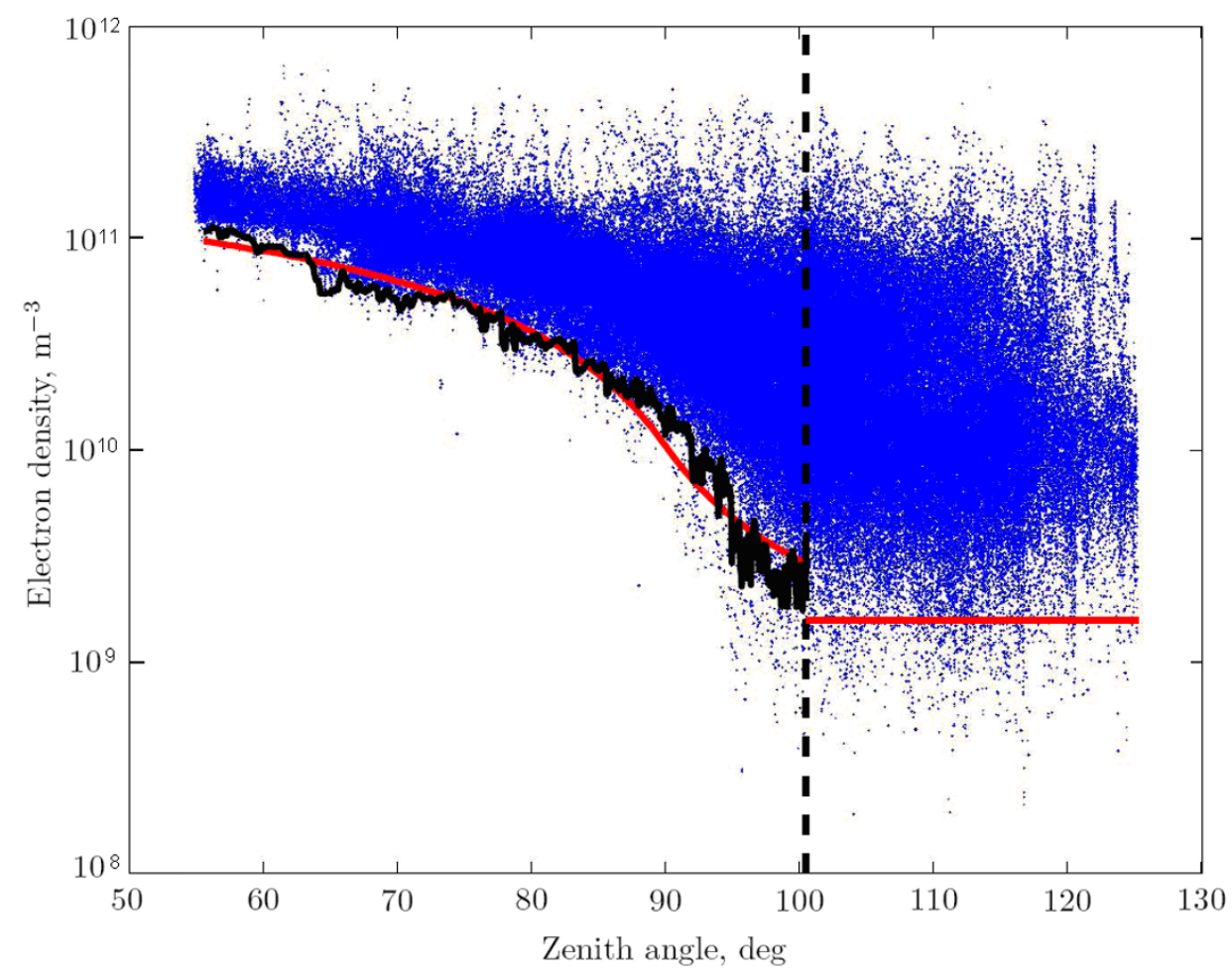

Fig. 2. All available electron densities at a pressure level of $10^{-3} \mathrm{~Pa}$ (typically $130 \mathrm{~km}$ ). The dashed line is the solar zenith angle of the shadow at that particular altitude. The low-density envelope (the two red lines with a smooth transition) is considered to represent the true quiet electron densities (TQ) as a function of solar zenith angle (Egger, 2004). 


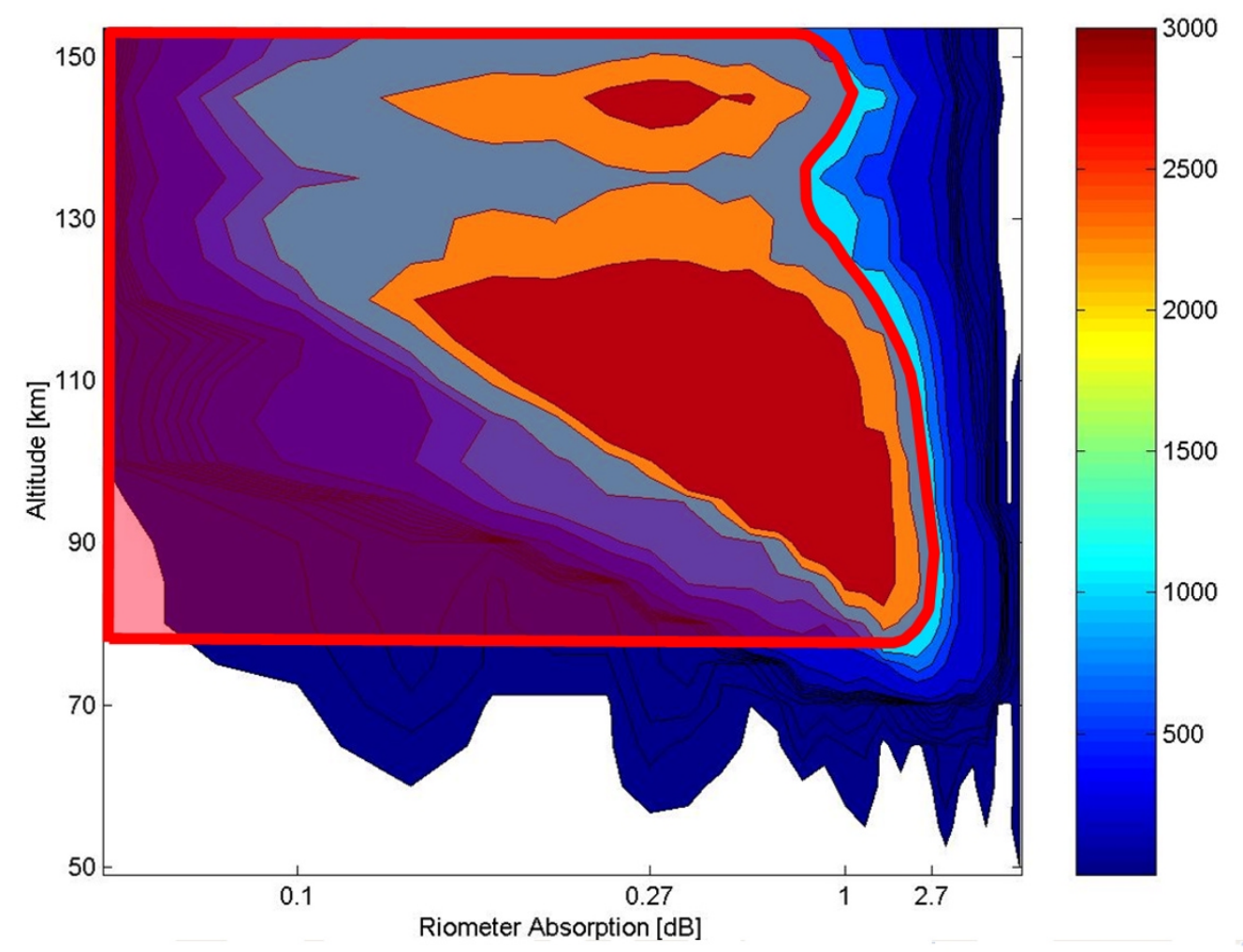

Fig. 3. Useful altitude-riometer range after the inclusion of TQ electron densities.

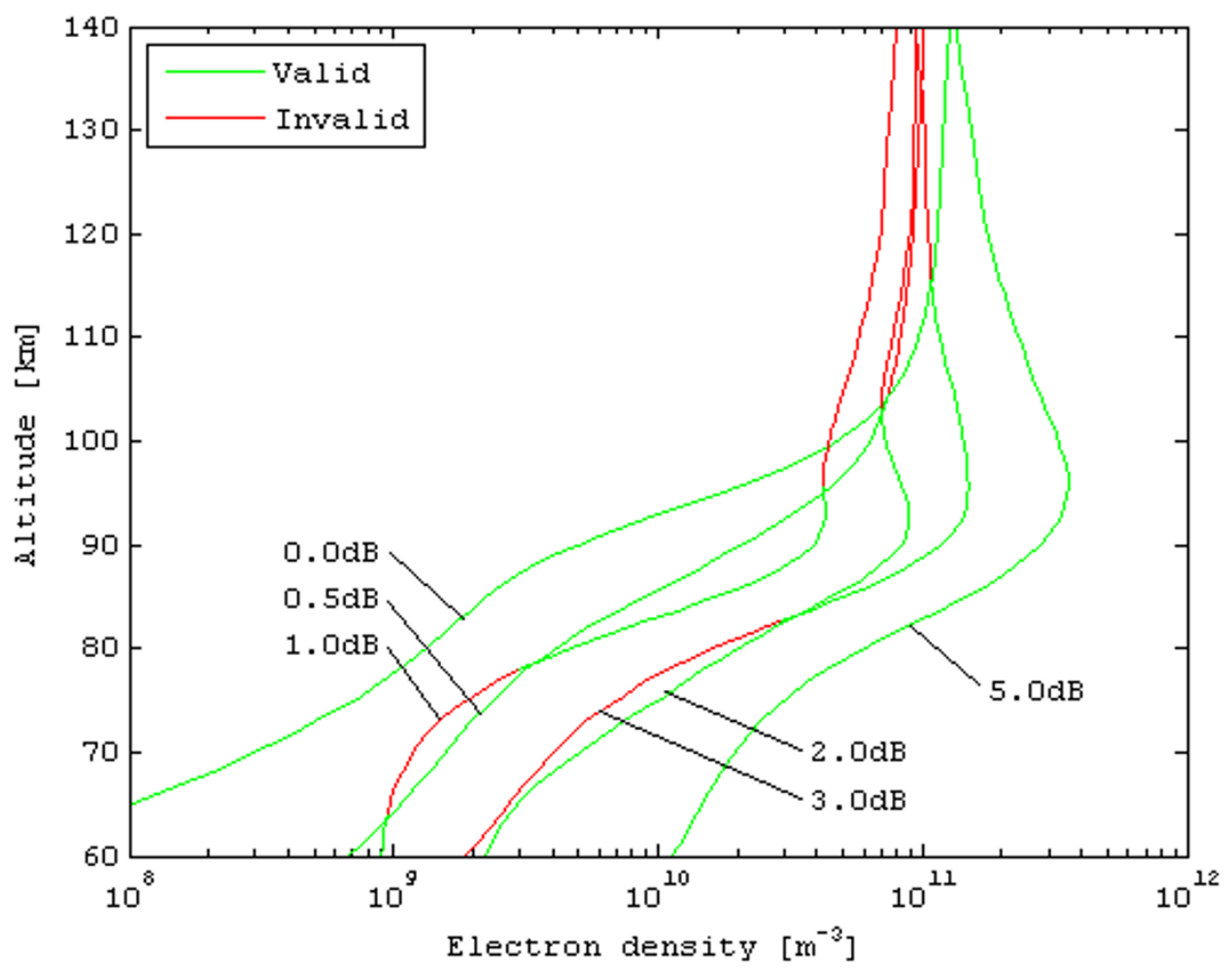

Fig. 4. Variation of electron densities according to IMAZ as a function of riometer absorption for otherwise median conditions (mid-April, $F_{10.7}=109$, zenith angle $89^{\circ}, a_{\mathrm{p}}=15$ ). 
Table 1. Range of geophysical parameters of the input data used for the IMAZ model.

\begin{tabular}{lccc}
\hline & Lower quartile & Median & Upper quartile \\
\hline Solar activity $F_{10.7}$ & 72 & 109 & 139 \\
Solar zenith angle $\chi,^{\circ}$ & 74 & 89 & 104 \\
Global magnetic index $a_{\mathrm{p}}$ & 7 & 15 & 27 \\
Riometer absorption, dB @ $27.6 \mathrm{MHz}, \mathrm{x}-$ mode & 0.16 & 0.29 & 0.56 \\
\hline
\end{tabular}

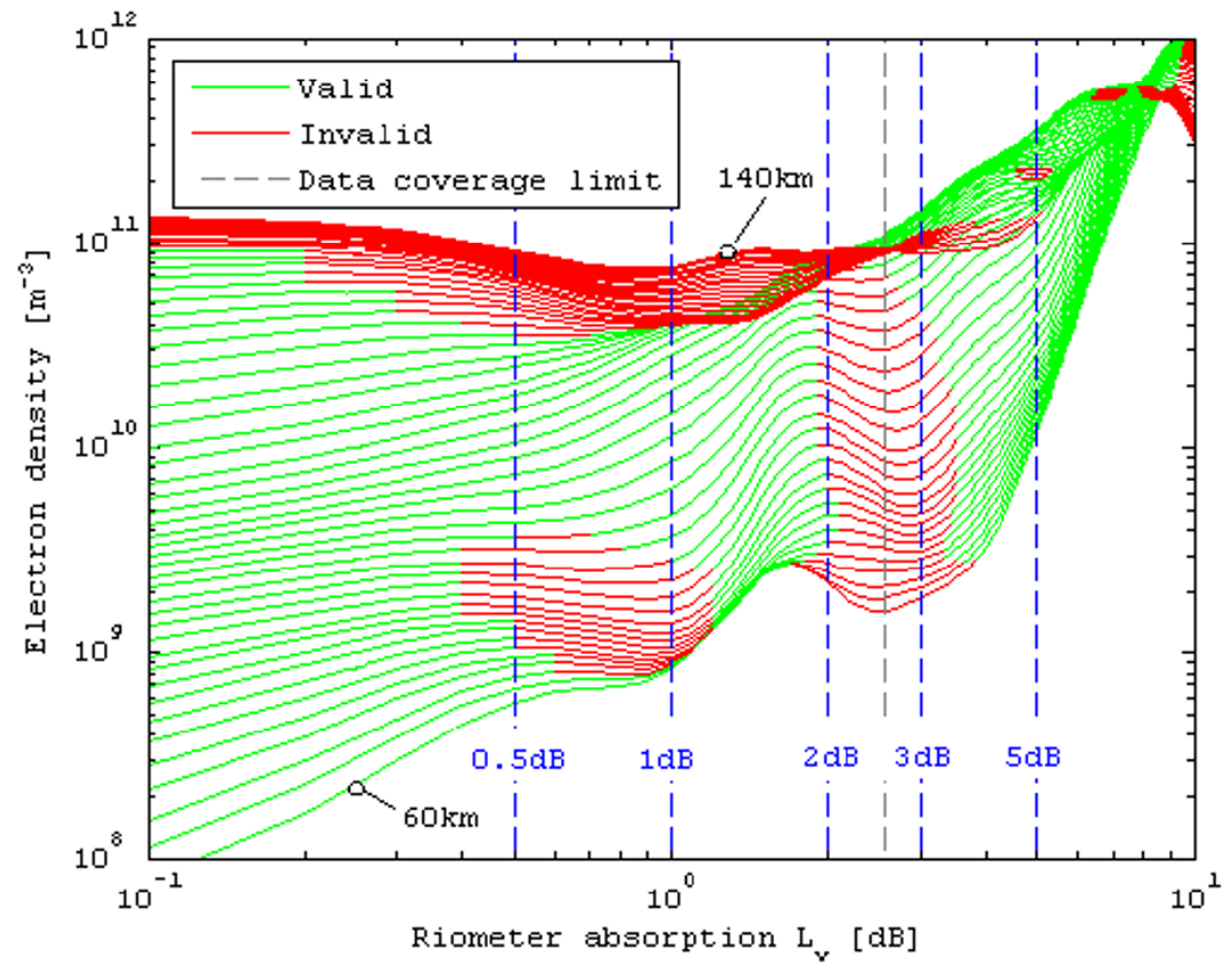

Fig. 5. Electron densities at constant altitudes (pressure levels) as a function of riometer absorption for the same conditions as in Fig. 4. The lines are at 12 logarithmically spaced pressure levels per decade between 60 and $140 \mathrm{~km}$.

is riometer absorption. In Fig. 4 the geophysical conditions are kept at the median values listed in Table 1 and the season is-somewhat arbitrarily-chosen to be midApril. In this time of the year both full night conditions (solar zenith angles $>98^{\circ}$ ) and a reasonably large variation of daytime zenith angles occurs. The varied parameter of the displayed curves is riometer absorption between 0 and $5 \mathrm{~dB}$ (at $27.6 \mathrm{MHz}, \mathrm{x}$-mode), expected to be indicative of the 70 to $90 \mathrm{~km}$ altitude range. The curve labelled $0 \mathrm{~dB}$ is identically with the True Quiet as described in the Introduction. Unexpected features are that at some heights electron densities decrease with increasing riometer absorption. Arguably riometer absorption is not a relevant parameter to describe the state of the $E$-region, whereas the decrease in the lower $D$-region may on the one hand simply be the result of insufficient number of data, but on the other hand also be due to the rather wide interpolation of IMAZ from TQ to fairly disturbed conditions (cf. Fig. 3 at $80 \mathrm{~km}$ ). Figure 5 is another representation of the same IMAZ results. Although a positive correlation of electron density and riometer absorption $\left(d N_{\mathrm{e}} / d L_{\mathrm{r}}>0\right)$ does not necessarily have to prevail at all altitudes, we will address the "invalid" red lines. In addition there is another definition of the valid range of the IMAZ predictions, namely whether the two disturbance parameters ( $L_{\mathrm{r}}$ and $a_{\mathrm{p}}$ ) can each be varied independently from the other. In Fig. $6 k_{\mathrm{p}}$ (essentially $a_{\mathrm{p}}$ on logarithmic scale) is plotted vs. riometer absorption. Clearly large riometer absorption is usually associated with large $a_{\mathrm{p}}$, whereas large $a_{\mathrm{p}}$ can occur without concurrently enhanced riometer absorption. The red line in that figure is a simple divider between the range which is well covered by $a_{\mathrm{p}}$ and $L_{\mathrm{r}}$ ("covered range") from that where the combination of the parameters only provides insufficiently coverage ("strange range"). For the all-median conditions the riometer limit of $2.8 \mathrm{~dB}$ is indicated in Fig. 5; clearly the invalid behaviour occurs when approaching the "strange range" and beyond, as well as above $100 \mathrm{~km}$ which is not characterised by absorption.

\section{Correction and Extrapolation}

The disturbed high latitude ionosphere is due to additional ionisation by energetic electrons or protons. Generally ionisation at lower altitudes is due to higher energies of these precipitating charged particles. Although the spectral shape of the energetic particles will change (steepen or harden), nonetheless enhanced fluxes in a specific energy 


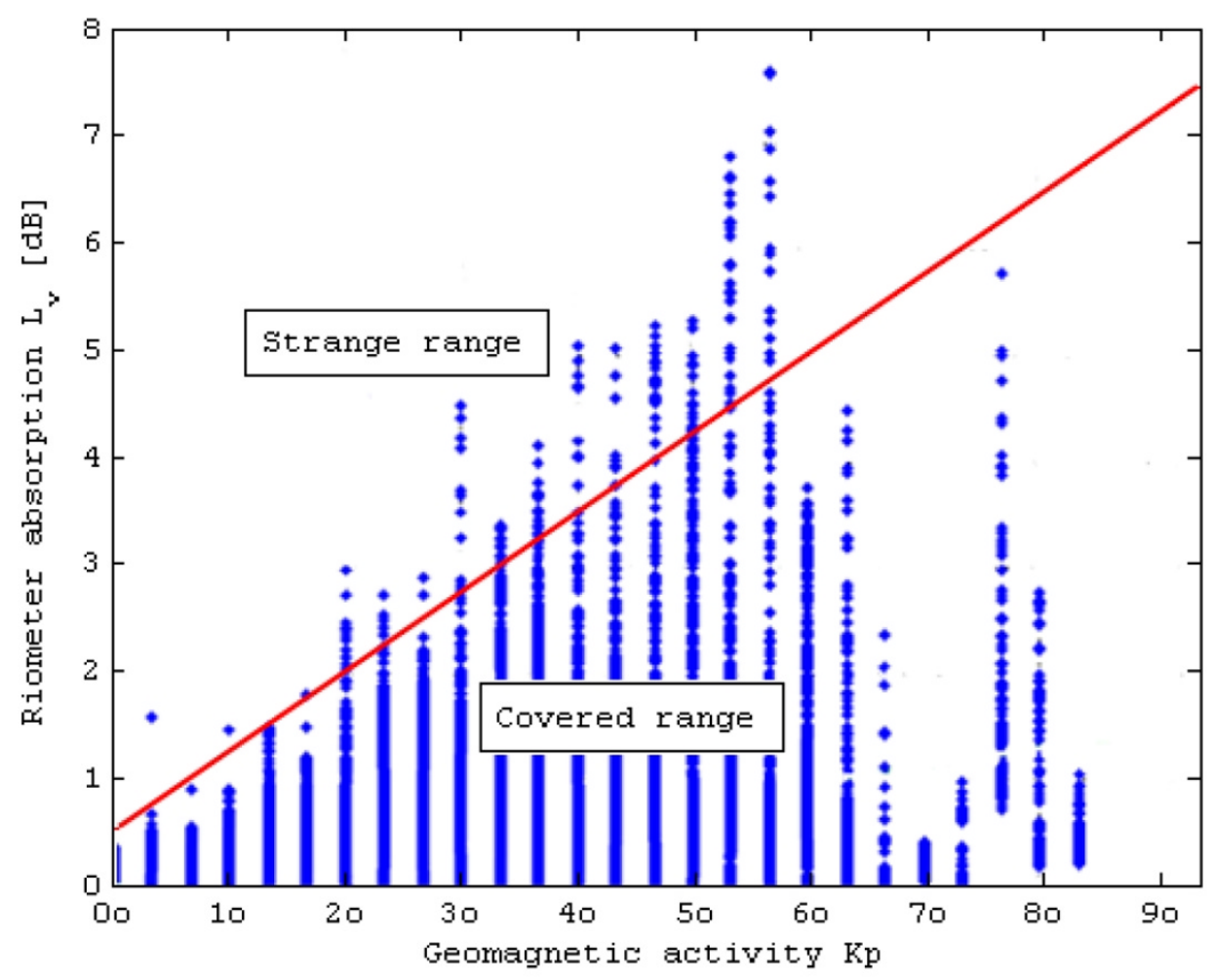

Fig. 6. Riometer absorption concurrent with geomagnetic disturbance in the data that entered the IMAZ model.

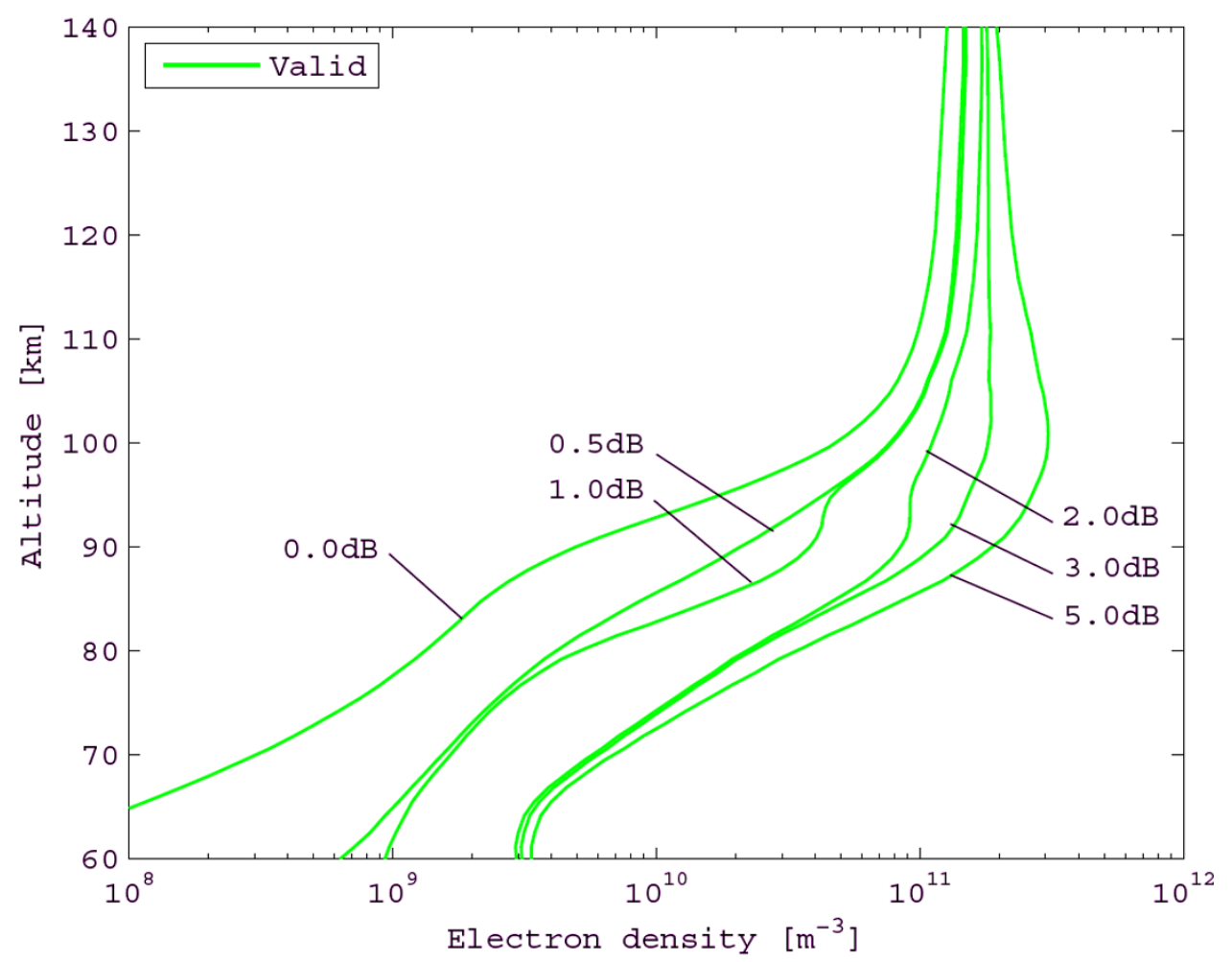

Fig. 7. Electron densities as a function of riometer absorption for median conditions according to the modified IMAZ model (cf. Fig. 4).

range will always also mean (more or less) enhanced fluxes in other parts of the spectrum, but certainly not lead to reduced fluxes. We therefore surmise that $d N_{\mathrm{e}} / d L_{\mathrm{r}}$ must always be positive with increasing $L_{\mathrm{r}}$. In order to "force"
IMAZ to obey this behaviour, we form the derivative at all altitudes (or pressure levels), leave out negative values and limit the acceptable range to $90 \%$ of the riometer limit for the prevailing $a_{\mathrm{p}}$ value. The gaps due to nega- 

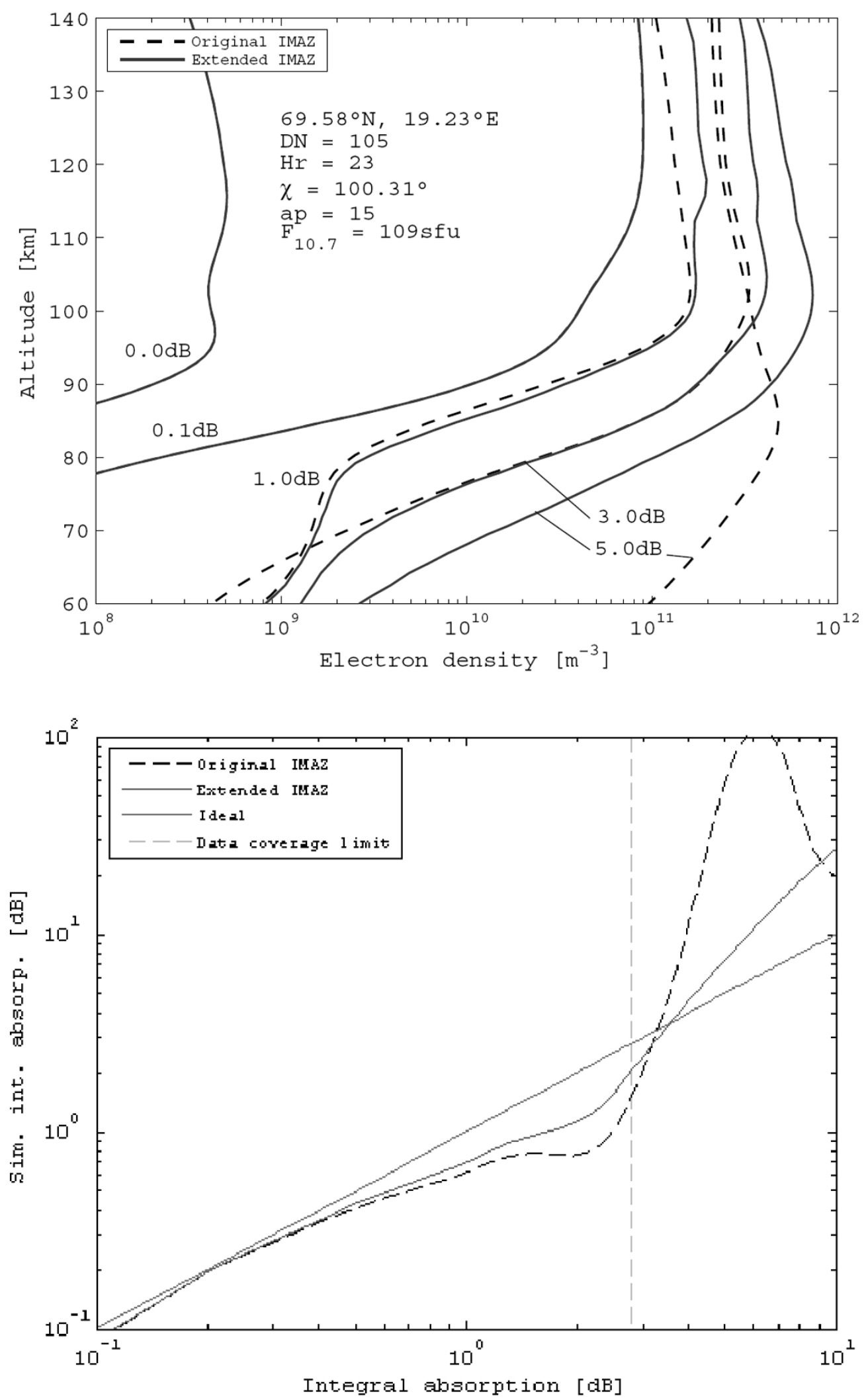

Fig. 8. Variation of night-time electron densities according to the original and the modified IMAZ model (upper panel), and the resulting simulated integral absorption (lower panel).

tive values are smoothed by cubic splines which allow zero, but not negative gradients (constant electron density). Beyond the riometer limit the gradients are extrapolated to $10 \mathrm{~dB}$ (or about $5 \mathrm{~dB}$ at today's more common frequency of
38.2 MHz). Figure 7 shows the electron density predictions for median conditions as in Fig. 4, but with the modifications described above.

Intuitively the new profiles look more as one would ex- 

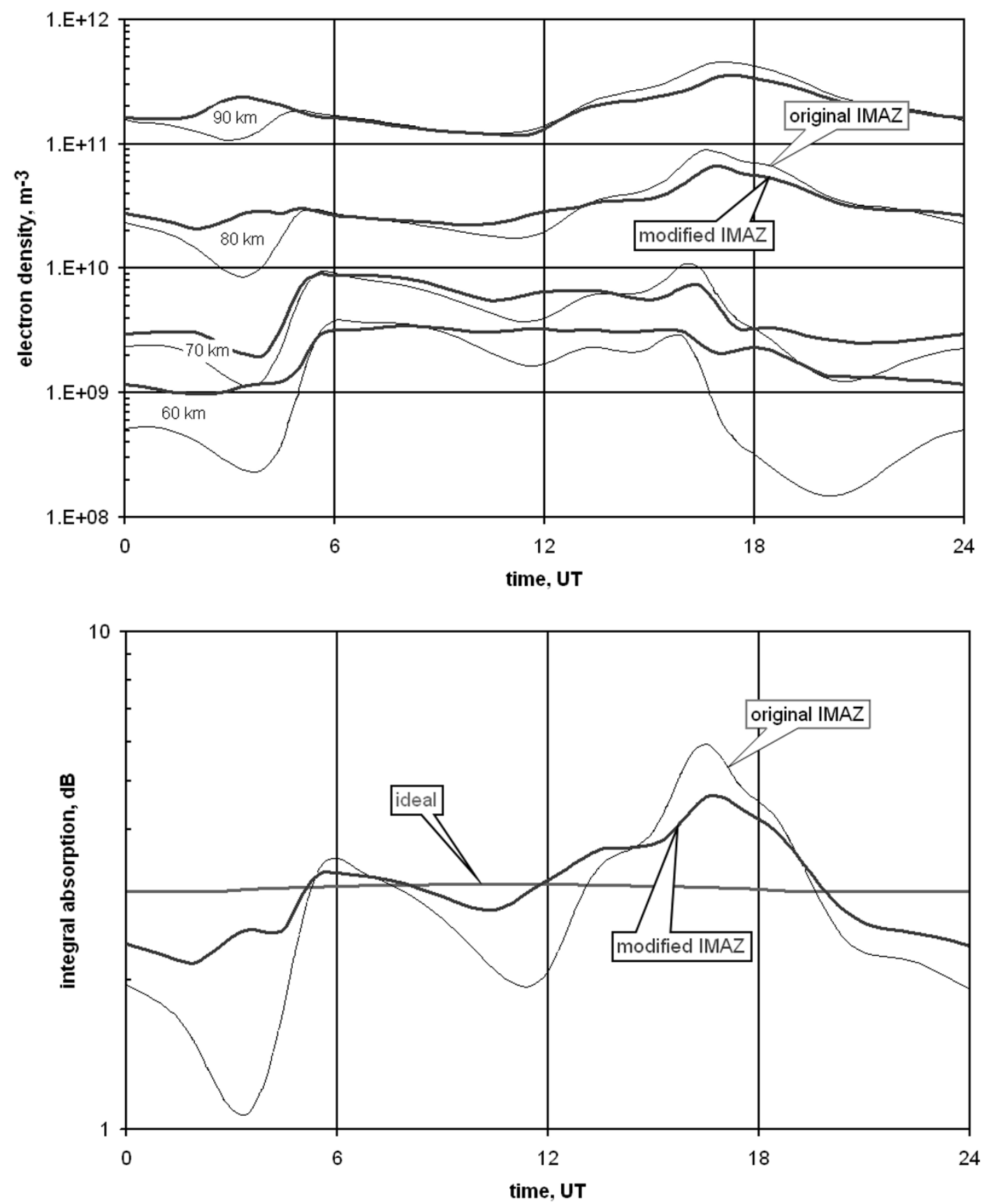

Fig. 9. Diurnal variation of electron densities at various heights for $3 \mathrm{~dB}$ riometer absorption (median conditions, mid-April) according to the original and the extended IMAZ model (upper panel), and the corresponding integral absorption (lower panel). Local noon is at 10:15 UT.

pect, but there are other ways to check if the modified IMAZ indeed performs better. Our $D$-region disturbance parameter is riometer absorption, i.e. the absorption of natural extraterrestrial radio sources due to the whole ionosphere. Strictly speaking riometer absorption is absorption beyond that of the quiet (solar controlled) ionosphere. The contribution of the TQ ionosphere is between 0.01 and $0.16 \mathrm{~dB}$ (Harrich et al., 2003). Model electron densities representative for a particular riometer absorption should ideally absorb extraterrestrial radio signals by that amount. In Fig. 8 we show the simulated integral absorption $L_{\mathrm{i}}$ (riometer values plus absorption due to the TQ ionosphere) vs. the integral absorption entered for the IMAZ prediction, together with the corresponding electron density profiles. Clearly the original IMAZ not only produces $E$-region densities that decrease with increasing riometer absorption, but perhaps more importantly the simulated absorption for large disturbances shows completely unrealistic values.

Large disturbances, i.e. electron densities significantly enhanced relative to $\mathrm{TQ}$, will still show a diurnal variation of the shape of the profile. This is to be expected owing to the different ion recombination chemistry, but also because the ionising spectra of energetic particles will in general have shapes that are typically different depending on the geomagnetic time. Nonetheless, the simulated riometer (or integral) absorption should throughout the day lead to the 
same value as was the input to the model. Figure 9 shows the diurnal variation of the simulated integral absorption for mid-April according to the original and the extended IMAZ for $3 \mathrm{~dB}$ riometer absorption. During mid-day the (ideal) integral absorption is about $0.1 \mathrm{~dB}$ larger than $3 \mathrm{~dB}$ owing to the absorption due to the TQ electron density. The original IMAZ produces large deviations from the ideal behaviour, notably at sunrise and sunset, whereas in the modified version there are still departures from the ideal behaviour, but considerably reduced.

\section{Conclusions}

The empirical model IMAZ is - as of today-probably unchallenged not least because of the huge amount of data that it is based on. The mathematical procedure of artificial neural networks (NN) provides good results inside the so-called input space, i.e. for well-covered geophysical condition. For predicting extreme situations, notably for large riometer absorption, the NN results from within the input space were extrapolated to values insufficiently or not at all covered by data. The plausibility of these extrapolated results not only intuitively appear sensible, but also the simulated riometer absorption is reasonably close to the riometer absorption the profiles are meant to represent.

As a further refinement/correction the sometimes large interpolation from True Quiet electron densities to the mea- sured ones was corrected. This is achieved by inhibiting that electron densities in the interpolated absorption range between TQ and measured data decreases with increasing absorption.

Acknowledgments. The work reported here expands the IMAZ model which was originally developed under the FWF Project M708-N06. The present extension makes use of more data, notably the ones obtained through Austrian Science Fund (FWF) Project 18560 (ECOMA).

\section{References}

Bilitza, D. and B. W. Reinisch, International Reference Ionosphere 2007: Improvements and new parameters, Adv. Space Res., 42(4), 599-609, 2008

Egger, G., Empirical model of the quiet polar cap ionosphere, MSc Thesis, Graz University of Technology, 2004.

Friedrich, M., M. Harrich, R. J. Steiner, K. M. Torkar, and F.-J. Lübken, The quiet auroral ionosphere and its neutral background, Adv. Space Res., 33(6), 943-948, 2004.

Harrich, M., M. Friedrich, S. R. Marple, and K. M. Torkar, The background absorption at high latitudes, Adv. Radio Sci., 1, 325-327, 2003.

McKinnell, L.-A. and M. Friedrich, A neural network-based ionospheric model for the auroral zone, J. Atmos. Sol. Terr. Phys., 69, 1459-1470, 2007.

M. Friedrich (e-mail: martin.friedrich@tugraz.at) and G. Landauer 